\title{
Immunological Analysis of the EDTA-soluble Antigens of Clostridium difficile and Related Species
}

\author{
By IAN R. POXTON* AND MARIE D. BYRNE \\ Department of Bacteriology, University of Edinburgh Medical School, Teviot Place, \\ Edinburgh EH8 9AG
}

(Received 7 May 1980)

\begin{abstract}
Antigens were extracted with EDTA from 32 strains representing 10 species of Clostridium. When these antigens were examined by an enzyme-linked immunosorbent assay, marked cross-reactions were observed between $C$. difficile, $C$. sordellii and $C$. bifermentans. The cross-reactive antigen, visualized by crossed immunoelectrophoresis, was carbohydrate.
\end{abstract}

\section{INTRODUCTION}

Until recently Clostridium difficile was regarded as an uncommon, non-pathogenic organism. It is part of the normal faecal flora of many neonates but is rarely found in adults (Larson et al., 1978). Since 1977, however, there has been an increasing number of reports to suggest that this organism is the major, if not the only, cause of antibiotic-associated colitis (Larson, 1979; Bartlett, 1979). There have also been recent reports that $C$. difficile is involved in chronic inflammatory bowel disease (Lamont \& Trnka, 1980; Bolton et al., 1980).

Two methods are currently available for the detection of $C$. difficile in the faeces: (i) it can be cultured on a highly selective medium (George et al., 1979); (ii) its toxin can be demonstrated in a faecal filtrate by a cytopathic effect on tissue monolayers. This effect can be neutralized with $C$. sordellii antitoxin (Rifkin et al., 1977). There is a need to develop an immunological method for the identification of $C$. difficile in faecal smears by direct microscopy. Before such a technique can be developed, cross-reactions between serologically related species must be investigated. Furthermore, a knowledge of the antigens of this species might allow the development of a serotyping scheme to elucidate the epidemiology of $C$. difficile (see Larson, 1979).

The present study examines serological relationships of $C$. difficile, $C$. sordellii and $C$. bifermentans by enzyme-linked immunosorbent assays and crossed immunoelectrophoresis. Clostridium sordellii and $C$. bifermentans, regarded by many as the same species, are commonly encountered in soil, sewage and the large bowel of man and animals. They are uncommon pathogens, but are occasionally associated with gas gangrene (Willis, 1969, 1977).

\section{METHODS}

Organisms and growth conditions. The strains of bacteria used were: $C$. difficile, N1, N3, N4, N5 and N6 (obtained from Dr S. Hafiz, University of Sheffield Medical School), MPRL2, 15, 40, 50 and 59 (isolated in the Bacteriology Department, University of Edinburgh), RIE11831 (isolated in the Royal Infirmary, Edinburgh), FAL11456 (isolated at Fife Area Laboratories, Kirkcaldy) and NCTC 11223; C. sordellii, NCTC 1340, NCTC 2914, NCTC 6800, NCTC 6801, NCTC 6927, NCTC 6929 and NCTC 8780; C. bifermentans, NCTC 1341, NCTC 6928 and three laboratory strains; C. perfringens, NCTC 1869, NCTC 3110, NCTC 3180 , NCTC 8237, NCTC 8239 and one laboratory strain; C. paraperfringens, a laboratory strain; C. fallax, NCTC 8380; C. sporogenes, NCTC 8594; C. novyi, a laboratory strain; C. chauvoei, NCTC 8070; C. absonum, a laboratory strain. 
All strains were cultured from a stationary phase broth culture in modified Robertson's cooked meat medium (Watt, 1973). Proteose peptone/yeast extract broth (Holbrook et al., 1977) was inoculated (2\%, v/v) and cultured for $16 \mathrm{~h}$ at $37^{\circ} \mathrm{C}$ by the standard anaerobic procedure of Collee et al. (1972). Sporulation was negligible under these conditions.

Extraction of antigens. Bacteria, cultured in $100 \mathrm{ml}$ medium (see above), were harvested by centrifugation at $2400 \mathrm{~g}$ for $20 \mathrm{~min}$ at room temperature and washed twice in phosphate buffered saline (PBS, $50 \mathrm{~mm}$-sodium phosphate buffer, pH 7.4 containing $0.15 \mathrm{M}-\mathrm{NaCl}$ ). The pellet was suspended in $4 \mathrm{ml}$ PBS containing $10 \mathrm{mM}$-EDTA and incubated for $30 \mathrm{~min}$ at $45^{\circ} \mathrm{C}$. The extracted cells were removed by centrifugation $(10000 \mathrm{~g}$, $10 \mathrm{~min}, 4^{\circ} \mathrm{C}$ ) and the supernatant fluid was dialysed twice against 21 volumes of PBS over $20 \mathrm{~h}$ at $4{ }^{\circ} \mathrm{C}$. Protein concentrations, after dialysis, were measured by the Lowry method. Antigens were stored at $-20^{\circ} \mathrm{C}$.

Preparation of antisera. Antisera against u.v.-killed, whole, washed bacteria were raised in New Zealand White rabbits as described previously for Bacteroides spp. (Poxton, 1979). Clostridium difficile NCTC 11223 and $C$. sordellii NCTC 1340 were used at the standard doses of $10^{9}$ cells throughout the injection schedule. However, for the toxigenic C. sordellii NCTC 8780 , the first three doses were $10^{6}$ cells, increasing to three doses of $10^{7}$ cells in the second week and boosted by one dose of $10^{7}$ cells in the fourth week.

Absorption of sera. Cells for absorption were cultured on blood agar for $18 \mathrm{~h}$ at $37^{\circ} \mathrm{C}$. They were carefully scraped from the surface, suspended in PBS and washed twice in PBS. Undiluted serum was added directly to the washed pellet at a ratio of $1 \mathrm{ml}$ of serum to bacteria from ten plates. The mixture was gently homogenized and incubated at $37^{\circ} \mathrm{C}$ for $30 \mathrm{~min}$. Bacteria were removed by centrifugation at $2400 \mathrm{~g}$ for $20 \mathrm{~min}$ at $20^{\circ} \mathrm{C}$.

Micro-enzyme-linked immunosorbent assay (ELISA). The EDTA-extracted antigen was diluted to a concentration of $30 \mu \mathrm{g}$ protein $\mathrm{ml}^{-1}$ in antigen buffer just prior to coating wells of microtitre plates. The method was as described previously (Poxton, 1979) except that the results were read in a Titretek Multiskan (Organon Teknika, St Neots). The end-point of the titration of antiserum (titre) was the first dilution with an $A_{405}$ value of less than 1.6 .

Crossed immunoelectrophoresis (CIE). The procedure was essentially the same as that described by Weeke $(1973 a)$. The EDTA-extracted antigens were made up to $2 \mathrm{mg}$ protein $\mathrm{ml}^{-1}$ in PBS and equilibrated by dialysis in CIE sample buffer (see below). Triton X-100 was added to the dialysed antigen at a concentration of $1 \%(\mathrm{v} / \mathrm{v})$. Antigens $(12 \mu \mathrm{l})$ were examined by CIE on $5 \times 5 \mathrm{~cm}$ glass slides using barbital/glycine/Tris buffer pH 8.8 (Weeke, $1973 \mathrm{~b}$ ). Buffer was used undiluted (ionic strength 0.08) in the electrode reservoirs, but in the gels and sample buffer it was diluted 1 in 4 with distilled water, and Triton X-100 was added to a concentration of $1 \%(\mathrm{v} / \mathrm{v})$. Gels contained agarose (BDH electrophoresis grade) at a concentration of $1 \%(\mathrm{w} / \mathrm{v})$. Electrophoresis was at $12.5 \mathrm{~V} \mathrm{~cm}^{-1}$ for 1.5 to $2 \mathrm{~h}$ in the first dimension and at $12 \mathrm{~V} \mathrm{~cm}^{-1}$ for $16 \mathrm{~h}$ in the second dimension, both at $4{ }^{\circ} \mathrm{C}$. Gels were pressed, washed and stained with Coomassie blue as described by Weeke $(1973 \mathrm{~b})$, or stained with the periodate-Schiff's reagents (Segrest \& Jackson, 1977).

Treatment of antigens. The following treatments were performed on the antigens and the effects on the CIE profiles were examined: (i) heat, $121^{\circ} \mathrm{C}$ for $15 \mathrm{~min}$; (ii) formalin, $20 \%\left(\mathrm{w} / \mathrm{v}\right.$ ) formaldehyde for $16 \mathrm{~h}$ at $20^{\circ} \mathrm{C}$ followed by dialysis against PBS for $18 \mathrm{~h}$ at $4{ }^{\circ} \mathrm{C}$; (iii) periodate, $0.1 \mathrm{M}-\mathrm{NaIO}_{4}$ for $16 \mathrm{~h}$ at $20^{\circ} \mathrm{C}$ in the dark; excess periodate was consumed by the addition of ethylene glycol and this was followed by dialysis against PBS for $18 \mathrm{~h}$ at $4{ }^{\circ} \mathrm{C}$. Untreated controls were included for treatments (ii) and (iii).

\section{RESULTS}

EDTA extracts were prepared from 32 strains representing ten species of Clostridium. Antisera raised against whole, washed cells of $C$. difficile NCTC 11223, C. sordellii NCTC 1340 and C. sordellii NCTC 8780 (a toxigenic strain) were titrated with the extracts in an enzyme-linked immunosorbent assay (ELISA). Cross-reactions were observed only between $C$. difficile, $C$. sordellii and $C$. bifermentans strains. The antigens extracted from these three species gave titres ranging between 3200 and 25600 when reacted with the antisera raised against the $C$. difficile strain and the two $C$. sordellii strains. A titre of less than 100 was obtained when antigens prepared from $C$. perfringens Types $\mathrm{A}$ to $\mathrm{E}, C$. paraperfringens, $C$. fallax, $C$. sporogenes, $C$. novyi, $C$. chauvoei and $C$. absonum were reacted with $C$. difficile or $C$. sordellii antisera. It was impossible to differentiate beween $C$. difficile, $C$. sordellii and $C$. bifermentans when EDTA-extracted antigens were titrated with unabsorbed sera. In an attempt to reduce the cross-reactions between species the sera were absorbed with whole cells of the cross-reactive species. This resulted in a more specific reaction but it was accompanied by a marked reduction in the titre of homologous 

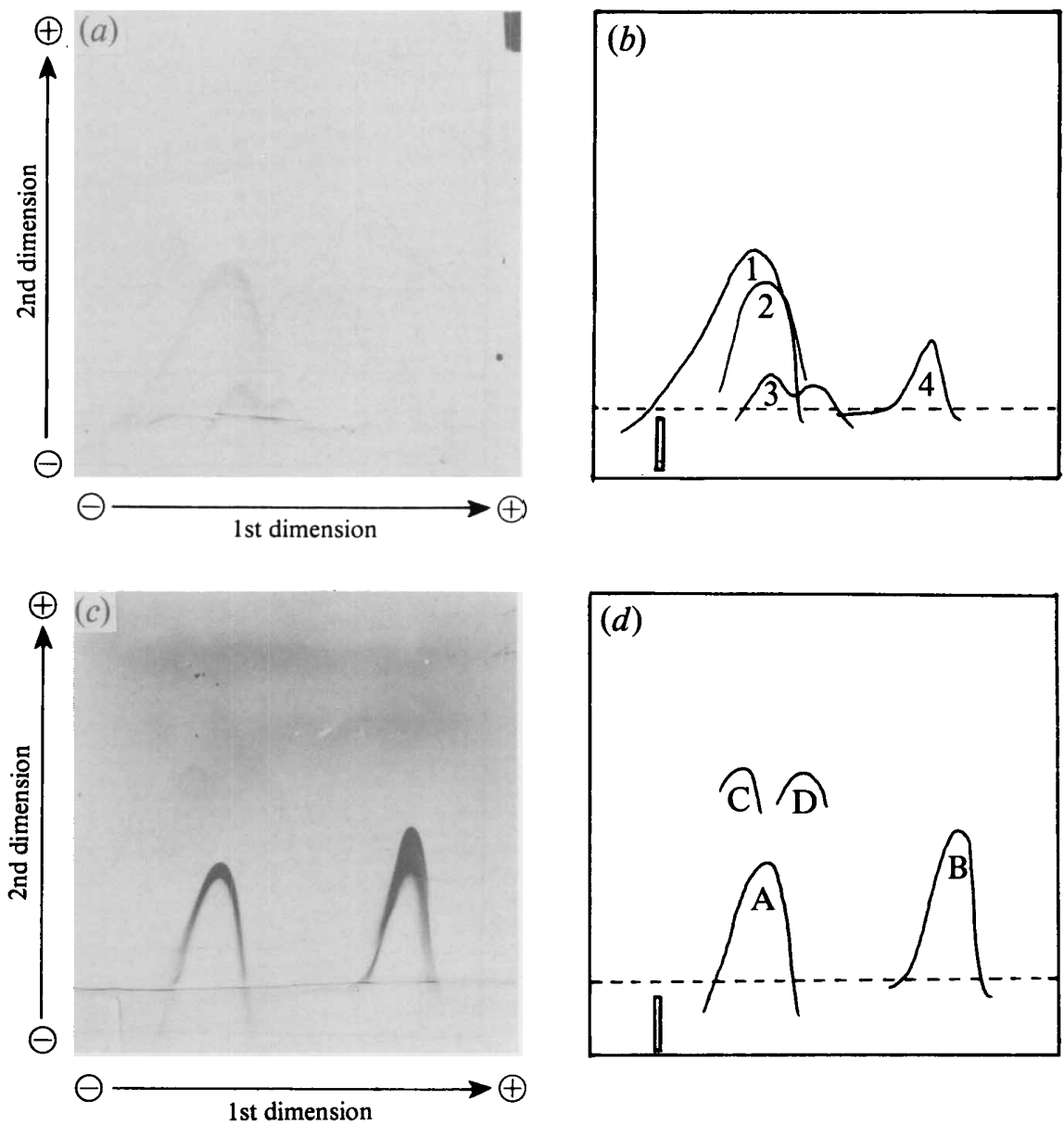

Fig. 1. Crossed immunoelectrophoresis of EDTA-extracted antigens from $C$. difficile NCTC 11223 and $C$. sordellii NCTC 8780 against homologous whole cell antisera: ( $a$, and drawing $b$ ) $12 \mu \mathrm{l}$ antigen from C. difficile, after electrophoresis in the 1st dimension, was run into agarose containing $63 \mu \mathrm{l}$ antiserum; (c, and drawing $d$ ) $12 \mu \mathrm{l}$ antigen from $C$. sordellii was run into agarose containing $500 \mu \mathrm{l}$ antiserum.

antigen/antibody reaction. This suggested that there were some species-specific antigens in the EDTA extracts but that other antigens were shared between these three species.

The antigen/antibody reactions demonstrated by ELISA were visualized by crossed immunoelectrophoresis (CIE). Figure 1 shows that the homologous antigen/antibody reactions for $C$. difficile NCTC 11223 and for $C$. sordellii NCTC 8780 are quite different from one another. Clostridium sordellii NCTC 1340 gave a reaction that was almost identical with that of strain NCTC 8780. In similar tests with $C$. bifermentans antigens run against $C$. sordellii antisera, the patterns were indistinguishable from those obtained with $C$. sordellii antigens.

Table 1 indicates the number and position of precipitin lines obtained with antigens prepared from 13 strains of $C$. difficile run against $C$. difficile NCTC 11223 antiserum. The positions of these precipitin lines are given by reference to the lines shown in Fig. $1(b)$. Line 2 is common for all strains tested, line 4 occurs frequently and lines 1 and 3 are less frequently demonstrable.

Clostridium difficile antigens reacted with $C$. sordellii antisera to give line 2 on all 

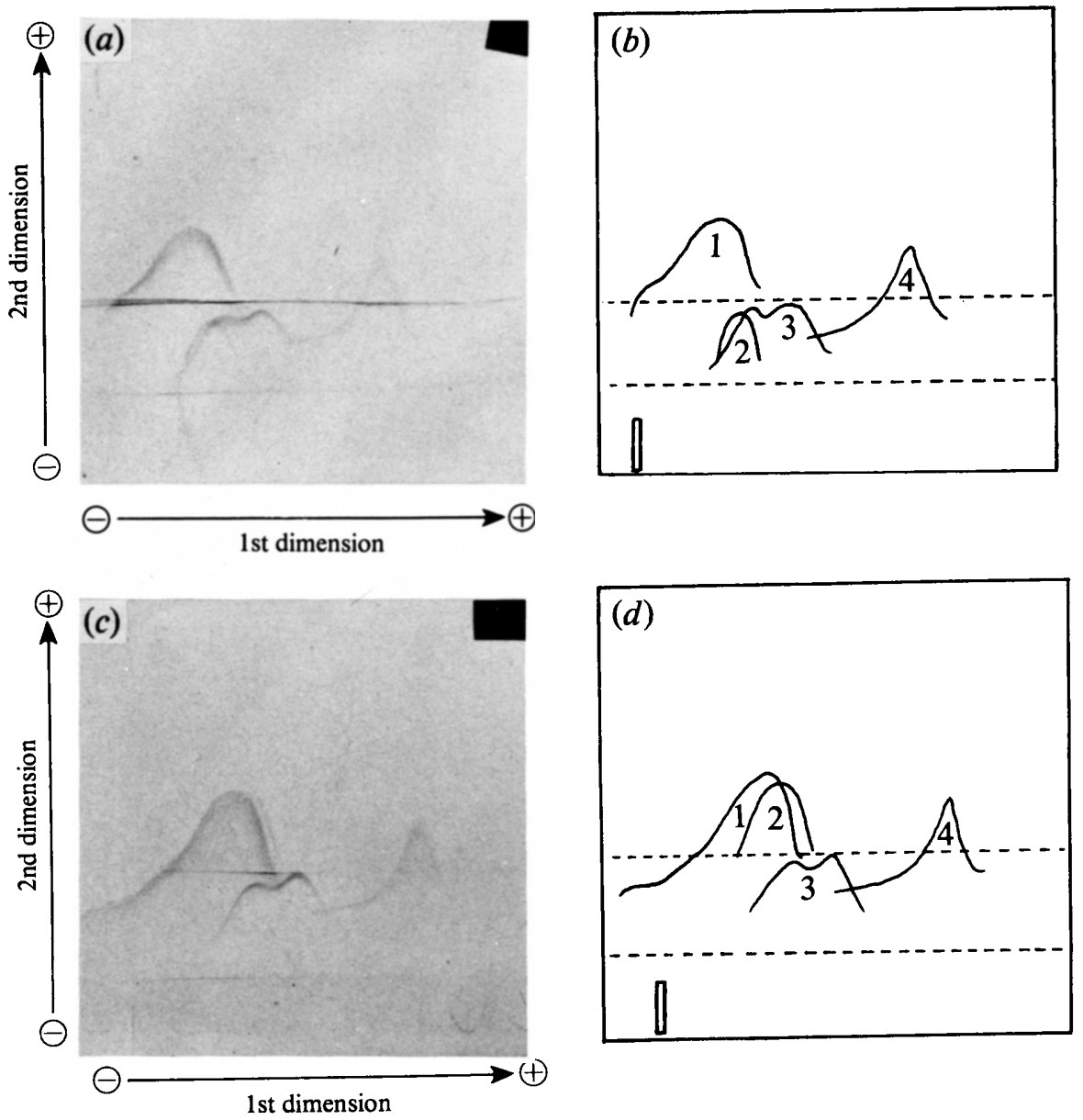

Fig. 2. Intermediate-gel crossed immunoelectrophoresis of $C$. difficile NCTC 11223 EDTA-extracted antigens: ( $a$, and drawing $b$ ) $12 \mu$ lantigen, after electrophoresis in 1st dimension, was run through a $1 \mathrm{~cm}$ intermediate gel containing $63 \mu \mathrm{l}$ antiserum to $C$. sordellii NCTC 8780 into a gel containing $48 \mu \mathrm{l}$ $C$. difficile NCTC 11223 antiserum; $(c$, and drawing $d)$ as above except the intermediate gel did not contain any serum. Peaks are numbered as in Fig. $1(b)$.

Table 1. Variation in EDTA-extracted antigens from 13 strains of $C$. difficile run against NCTC 11223 antiserum in crossed immunoelectrophoresis

Strain of $C$. difficile Precipitin lines in EDTA extract*

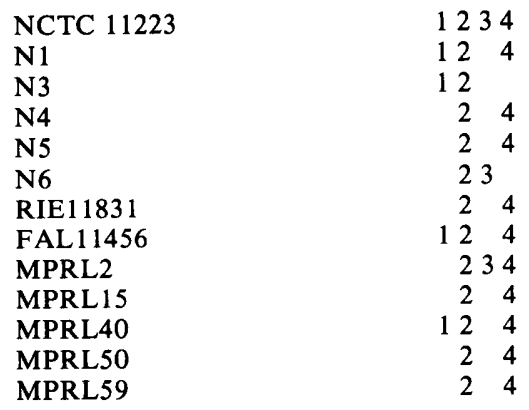

* Precipitin lines numbered as in Fig. $1(b)$. 
occasions. No other precipitin line occurred in these tests. However, C. sordellii antigens reacted with the $C$. difficile antiserum to give two lines in positions A and B shown in Fig. $1(d)$. This suggested that line 2 and line $\mathbf{A}$ are lines of cross-reaction and may be identical. This was further investigated by exploiting the intermediate gel procedure of Axelsen (1973).

Clostridium difficile antigen was run through an intermediate gel containing $C$. sordellii antiserum and then into a gel containing $C$. difficile antiserum (Fig. $2 a, b$ ). In a control, the intermediate gel contained no antiserum (Fig. $2 c, d$ ). Lines 1, 2, 3 and 4 developed in the test and control. However, the presence of the C. sordellii antiserum in the intermediate gel held back the precipitin line 2 . The other lines were identical in the test and the control. The position of line 3 at the intermediate gel level is explained by back diffusion of the antiserum.

The converse experiment was done with $C$. sordellii antigen run through an intermediate gel containing $C$. difficile antiserum into gel containing $C$. sordellii antiserum. In this case both lines A and B (see Fig. 1d) were held back by the serum in the intermediate gel.

The EDTA-extracted antigen of $C$. difficile used in these studies contained approximately $90 \%$ protein and $10 \%$ carbohydrate as estimated by the Lowry method and by the method of Dubois et al. (1956), respectively. Examination by sodium dodecyl sulphate-polyacrylamide gel electrophoresis showed that it contained at least 25 polypeptides. In an attempt to characterize the antigens that were visualized by CIE a number of chemical and physical treatments were performed (see Methods for details). (i) After heating, only line 2 remained. (ii) After treatment with formalin, only line 2 was unchanged; lines 3 and 4 were lost and line 1 was diffuse and changed in shape. (iii) After treatment with periodate, lines 2 and 4 were lost. In an untreated control, which was dialysed in the same way as in treatments (ii) and (iii), line 4 was also lost. This suggested that the antigen which precipitated in line 4 was either extremely labile or was lost during extensive dialysis. All lines except line 4 stained with the periodate-Schiff's reagents in an untreated control that had not been dialysed.

\section{DISCUSSION}

If the composition of the clostridial cell surface is similar to that of other Gram-positive bacteria, the surface antigens will include a range of proteins and possibly capsular material, and teichoic acid components or their analogues associated with the cell wall and cytoplasmic membrane. In the present study, EDTA was chosen to solubilize antigens from $C$. difficile and related species because it should solubilize protein and perhaps membrane teichoic acid without the breakage of any covalent bonds and without the extraction of wall teichoic acids; a considerable advantage is that autolysis is apparently inhibited by EDTA (unpublished observation).

All of the strains of $C$. difficile, $C$. sordellii and $C$. bifermentans examined share a common EDTA-extractable antigen which is probably carbohydrate; it is thermostable, inactivated by periodate and stains with the periodate-Schiff's reagent. In addition, all the strains of $C$. difficile had at least one other protein or possibly glycoprotein antigen complex that appears to be specific for $C$. difficile. It should be possible to exploit this finding to raise a specific $C$. difficile antiserum that will not cross-react with the $C$. sordellii-bifermentans group. In addition, the EDTA-extractable antigens may provide a basis for a sero-typing system of epidemiological value in tracing $C$. difficile infections.

The known serological relationships between $C$. bifermentans and $C$. sordellii (Huang, 1959, cited by Willis, 1977) are reflected in our finding that the EDTA-extracted antigens of these two species were indistinguishable by ELISA and CIE procedures. The relationship of $C$. difficile to the bifermentans-sordellii complex, suggested by the cross-neutralization of its toxin by $C$. sordellii antitoxin, is therefore paralleled by the somatic antigenic relationships that our studies have revealed.

This study was supported by a grant (no. K/MRS/50/C247) from the Scottish Home and Health Department. We are grateful to Professor J. G. Collee for his interest and advice. 


\section{REFERENCES}

Axelsen, N. H. (1973). Intermediate gel in crossed and in fused rocket immunoelectrophoresis. Scandinavian Journal of Immunology 2, Suppl. 1, 71-77.

Bartlett, J. G. (1979). Antibiotic-associated colitis. Clinics in Gastroenterology 8, 783-801.

Bolton, R. P., SherRifF, R. J. \& ReAd, A. E. (1980). Clostridium difficile associated diarrhoea: a role in inflammatory bowel disease. Lancet i, 383-384.

Collee, J. G., Watt, B., Fowler, E. B. \& Brown, R. (1972). An evaluation of the Gas-Pak system in the culture of anaerobic bacteria. Journal of Applied Bacteriology 35, 71-82.

Dubois, M., Gilles, K. A., Hamilton, J. K., Rebers, P. A. \& Sмiтh, F. (1956). Colorimetric method for determination of sugars and related substances. Analytical Chemistry 28, 350-356.

George, W. L., Sutter, V. L., Citron, D. \& FINEGOLD, S. M. (1979). Selective and differential medium for isolation of Clostridium difficile. Journal of Clinical Microbiology 9, 214-219.

Holbrook, W. P., Duerden, B. I. \& Deacon, A. G. (1977). The classification of Bacteroides melaninogenicus and related species. Journal of Applied Bacteriology 42, 259-273.

LAMONT, J. R. \& TRNKA, Y. M. (1980). Therapeutic implications of Clostridium difficile during relapse of chronic inflammatory bowel disease. Lancet i, 381-383.

LARSON, H. E. (1979). Pseudomembranous colitis is an infection. Journal of Infection 1, 221-226.

Larson, H. E., Honour, P., Price, A. B. \&
Borriello, S. P. (1978). Clostridium difficile and the aetiology of pseudomembranous colitis. Lancet i, $1063-1066$.

Poxton, I. R. (1979). Serological identification of Bacteroides species by an enzyme-linked immunosorbent assay. Journal of Clinical Pathology 32, 294-298.

Rifkin, G. D., Fekety, F. R., Silva, J. \& Sack, R. B. (1977). Antibiotic-induced colitis: implication of a toxin neutralised by Clostridium sordellii antitoxin. Lancet ii, 1103-1106.

Segrest, J. P. \& JACkson, R. L. (1972). Molecular weight determination of glycoprotein by polyacrylamide gel electrophoresis in SDS. Methods in Enzymology 28, 54-63.

WATt, B. (1973). The influence of carbon dioxide on the growth of obligate and facultative anaerobes on solid media. Journal of Medical Microbiology 6, 307-314.

WeEke, B. (1973a). Crossed immunoelectrophoresis. Scandinavian Journal of Immunology 2, Suppl. 1, 47-56.

WEEKE, B. $(1973 b)$. General remarks on principles, equipment, reagents and procedures. Scandinavian Journal of Immunology 2, Suppl. 1, 15-35.

Willis, A. T. (1969). Clostridium bifermentans and Clostridium sordellii. In Clostridia of Wound Infections, pp. 218-234. London: Butterworths.

Willis, A. T. (1977). Characteristics of the pathogenic and related clostridia. In Anaerobic Bacteriology: Clinical and Laboratory Practice, 3rd edn, pp. 111-172. London: Butterworths. 